\title{
Choosing variable-frequency drive systems for the mining process units
}

\author{
Natalia Kugusheva ${ }^{1}$, Alexander Semenov ${ }^{1, *}$, Ilya Yakushev $^{1}$, Svetlana Pavlova ${ }^{2}$, \\ Ayaal Egorov ${ }^{3}$, and Oleg Fedorov ${ }^{4}$ \\ ${ }^{1}$ North-Eastern Federal University named after Ammosov, Institute of Mathematics and Informatics, \\ 677000 Yakutsk, Russia \\ ${ }^{2}$ Mirny Polytechnic Institute, the branch of North-Eastern Federal University named after Ammosov, \\ 678170 Mirny, Russia \\ ${ }^{3}$ ALROSA PJSC, 678170 Mirny, Russia \\ ${ }^{4}$ Nizhny Novgorod State Technical University named after Alekseev, 603950 Nizhny Novgorod, \\ Russia
}

\begin{abstract}
Mining enterprises are energy intensive facilities. The capacity of single technological units can reach $5 \mathrm{MW}$. Variable-frequency drive systems are often used to set them in motion. The paper analyzes the features of choosing and using variable-frequency drives under diamond mining conditions. The study objective is to formulate and formalize the problems of introducing and operating variable-frequency drives at diamond-mining enterprises to further develop and implement guidelines for improving the performance of this drive type. To achieve this objective, the use of variable frequency drives in various process units of diamond mining should be studied and analyzed. The units are considered, for which in recent years, electric drive systems have been groundlessly (according to the authors) chosen by the engineering staff of enterprises. A technical and economic comparison of low-voltage frequency converters with the same power but different control modes is performed. The economic indicators of introducing high-voltage and low-voltage frequency converters into an existing electric drive system are calculated and represented as a comparative table. Conclusions are made on the need to proceed with the research and develop guidelines for implementing frequency converters at diamond-mining enterprises.
\end{abstract}

\section{Introduction}

The use of a variable-frequency drive (VFD) to improve the energy efficiency of industrial processes with the right approach to the implementation and further operation of an electric drive (ED) system may give a multiplicative economic effect [1-3]. Indeed, along with power savings $[4,5]$, high-quality control over the energy transformation and transmission through the use of VFDs allows achieving the following results: increasing the productivity of actuators by suggesting qualitatively new solutions to technical problems based on

\footnotetext{
* Corresponding author: as.semenov@,s-vfu.ru
} 
automating processes [6]; reducing the cost of maintenance and repair of process equipment due to smoother transient processes and the elimination of excess energy dissipation in the drive mechanism assemblies and elements [7-9]; extending the service life of electric motors (EM) and actuators [10, 11].

All above stipulates the widespread use of VFDs at mining enterprises, especially processing plants. The mechanisms using VFDs can be conditionally divided into two groups. The first one comprises units, in which the automatic speed control based on any process parameter (fluid pressure in the pipeline, fluid level in the sump, air depression in the ventilation duct, etc.) allows saving energy [12-15]; these include pumps and fans. The second group is the mechanisms, the speed of which should be controlled to ensure the required process unit operating modes $[16,17]$. This group comprises, e.g., mine hoists and dredge trip spotting hoists.

\section{Research objective and problems}

The research objective is to formulate the problems of operating a variable-frequency drive under the diamond mining conditions to further develop and implement guidelines for improving the efficiency of this drive type. To achieve this objective, the practice of using variable-frequency drives in various process units of diamond mining should be studied and analyzed, and technical and economic indicators of various VFD systems should be calculated and provided.

\section{Research results}

The efficiency of using high-voltage frequency converters (FCs) in the electric drive systems of the main fan unit of an underground mine and the main slurry pumping unit of the processing plant has been analyzed in [18-20]. As a result of implementing VFDs at these plants, not only significant power saving has been achieved but also, e.g., at a slurry pumping unit, the cost of maintenance and repair of the pump and pipelines has been reduced due to smoother transient processes and eliminating fluid hammer.

Herewith, there is also a negative practice of implementing and operating variablefrequency drives. Thus, e.g., in 2017, under the retrofitting plan, the FCs of the actuators of dredge No. 203 at the Irelyakh mine of ALROSA PJSC's Mirny Mining and Processing Division were replaced. On almost all mechanisms, the newly installed converters coped with their tasks, except for the dredge fore trip spotting hoists. The fact is that when these hoists operate, one of them is unwound, while the other is wound up. This process requires maintaining a certain tension of the ropes, which are fixed to the banks. Otherwise, the dredge maneuvering will be accompanied by the breakdown of the bank guys, which in turn leads to increasing dredge downtime and the guy restoring costs. Obviously, the solution to the problem of controlling the tension of the dredge fore trip spotting hoist ropes requires ensuring torque control of the ED system. In the given example, this problem has been solved only a year after implementing FCs, i.e. during a year, the dredge has operated at unreasonable costs. The paper authors analyzed this case and found two key reasons why it happened. The first one was incomplete information on the mechanisms to be controlled by the ED system, provided to the supplier when purchasing new FCs. The second reason was the poor supplier's experience in implementing FCs on the dredge actuators and its failure to perform a detailed survey of the facility.

Table 1 gives a comparison of the performance of various low-voltage converters with approximately the same power. This table shows that the difference in the converter cost may vary significantly. The frequency converter cost varies depending on the configuration, 
the availability of additional expansion boards, the IP rating, and other factors. Thus, e.g., the vector control option significantly increases the converter cost. This is justified by the ability of such control to maintain the given motor torque at any speed, which significantly expands the FC application area, i.e. such a converter is a perfect choice, e.g., for the ED system of mechanisms requiring the development of high torque at low speed. The possibility to maintain the given torque expands the speed control range and significantly improves the control over the EP system in general, which in turn allows using VFDs in complex process units requiring high accuracy [21-23].

Table 1. Comparison of the Performance of Low-Voltage Frequency Converters.

\begin{tabular}{|c|c|c|c|c|}
\hline Parameter & $\begin{array}{c}\text { VESPER } \\
\text { EI-9011 }\end{array}$ & $\begin{array}{c}\text { VESPER } \\
\text { EI-P7012 }\end{array}$ & $\begin{array}{c}\text { ABB } \\
\text { ACS550 }\end{array}$ & $\begin{array}{c}\text { DANFOSS } \\
\text { FC 302 }\end{array}$ \\
\hline Power, kW & 220 & 220 & 200 & 200 \\
\hline Voltage, V & 380 & 380 & 380 & 380 \\
\hline Voltage tolerance, \% & $+10,-15$ & $+10,-15$ & $+10,-15$ & $+10,-10$ \\
\hline Motor control method & $\begin{array}{c}\text { Scalar or } \\
\text { vector }\end{array}$ & Scalar & $\begin{array}{c}\text { Scalar or } \\
\text { vector }\end{array}$ & $\begin{array}{c}\text { Scalar or } \\
\text { vector }\end{array}$ \\
\hline $\begin{array}{c}\text { Speed maintaining accuracy } \\
\text { (with feedback), \% }\end{array}$ & \pm 0.2 & \pm 0.1 & \pm 0.1 & \pm 0.15 \\
\hline $\begin{array}{c}\text { min rated output current } \\
\text { overload margin, \% }\end{array}$ & 150 & 120 & 150 & 160 \\
\hline $\begin{array}{c}\text { Torque maintaining accuracy } \\
\text { (with feedback) } \%\end{array}$ & \pm 5 & - & \pm 2 & \pm 5 \\
\hline $\begin{array}{c}\text { Cost, kRUB } \\
\text { kRUB }\end{array}$ & 982.3 & 702.7 & $1,251.5$ & $1,584.3$ \\
\hline $\begin{array}{c}\text { Cost of 1 set of spare parts, } \\
\text { kRUB }\end{array}$ & 343.8 & 245.9 & 438.0 & 554.5 \\
\hline \begin{tabular}{c} 
Annual maintenance cost, \\
\hline
\end{tabular} & 108.0 & 77.3 & 137.7 & 174.3 \\
\hline
\end{tabular}

High voltage converters differ more significantly in cost. This difference is determined by circuitry solutions in the power FC section. High voltage converters available on the market can be classified into three groups by the type of power conversion, i.e. direct, cascade, and multilevel converters. The design of modern cascade and direct power converters involves the use of high-voltage thyristors or transistors, the cost of which may reach EURk 17, which in turn leads to a significant increase in the converter cost.

Multilevel converters are much cheaper since, in fact, they consist of so-called lowvoltage H-bridges, the circuit of which is built on low-voltage IGBT transistors. Since 2017, even the FC industry leaders such as ABB and Rockwell Automation have started manufacturing high-voltage multilevel converters in line with market conditions.

Considering that currently, a lot of domestic and foreign FC manufacturers compete on the market, each of which offers its technical solutions in the field of VFD, a customer can always choose exactly the converter, the use of which on a particular unit is technically and economically justified. I.e., on the one hand, the converter should meet the process requirements for the ED system operating modes, and on the other hand, it should not have extra functions. Thus, e.g., most fan and pumping units do not require a special expansion of the speed control range, high accuracy, and speed, nevertheless, at many industrial facilities of PJSC ALROSA, such units use converters with extra functions not needed in this particular case [24, 25].

Let us give an example of implementing a high-voltage VFD in a pumping unit with a capacity of $315 \mathrm{~kW}$ of the processing plant (PP) No. 3 of ALROSA JSC's Mirny Mining 
and Processing Division (PJSC). To save capital investments for modernization and considering the under-capacity of the intrashop $0.4 \mathrm{kV}$ networks, the power service personnel of the PP No. 3 have decided to introduce high-voltage frequency converters. The authors performed calculations for two VFD implementation options with high-voltage and low-voltage converters. The calculations have been performed for an operating pumping unit, where using a VFD is planned to improve efficiency. Before the modernization, the pumping unit was driven by an uncontrolled ED system based on a high-voltage asynchronous motor with a direct-on-line start. Table 2 gives a comparison of economic indicators for high-voltage and low-voltage VFDs with a capacity of $315 \mathrm{~kW}$.

Table 2. Comparative Table of the Economic Indicators for Two VFD Types.

\begin{tabular}{|c|c|c|}
\hline Cost Item & $\begin{array}{c}\text { Cost, kRUB } \\
\text { for High } \\
\text { voltage VFD }\end{array}$ & $\begin{array}{l}\text { Cost, kRUB } \\
\text { for Low } \\
\text { voltage VFD }\end{array}$ \\
\hline \multicolumn{3}{|c|}{ Capital investment } \\
\hline Frequency converter, $1 \mathrm{pc}$ & $4,799.5$ & $2,438.4$ \\
\hline Low voltage motor, $1 \mathrm{pc}$ & - & 670.7 \\
\hline Substation $630 / 6 / 0.4,2$ pcs & - & 397.7 \\
\hline Power cable, $600 \mathrm{~m}$ & - & $1,730.6$ \\
\hline Materials & 100.0 & 100.0 \\
\hline Electrical work & 184.6 & 450.0 \\
\hline Commissioning & 621.4 & 460.1 \\
\hline Total & $5,705.5$ & $6,247.5$ \\
\hline \multicolumn{3}{|c|}{ Operating costs } \\
\hline $\begin{array}{l}\text { The converter maintenance and repair } \\
\text { costs per year }\end{array}$ & 539.4 & 230.0 \\
\hline $\begin{array}{l}\text { Spare parts, tools, and appliances for } \\
\text { the converter, set }\end{array}$ & $1,696.3$ & 946.8 \\
\hline Total & $2,235.7$ & $1,176.8$ \\
\hline \multicolumn{3}{|c|}{ Estimated economic effect of implementation } \\
\hline $\begin{array}{l}\text { Savings due to reduced power } \\
\text { consumption (compared to } \\
\text { uncontrolled drive), per year }\end{array}$ & $2,197.6$ & $2,040.6$ \\
\hline $\begin{array}{l}\text { Savings due to lower operating costs } \\
\text { for pumps and the pumped liquid } \\
\text { distribution system (compared to } \\
\text { uncontrolled drive), per year }\end{array}$ & 986.4 & 986.4 \\
\hline Total & $3,184.0$ & $3, \mathbf{3 2 7 . 0}$ \\
\hline
\end{tabular}

As Table 2 shows, for this pumping unit, implementing a low-voltage VFD would be more expedient since the capital costs are approximately comparable. But in this case, the cheapest high-voltage and one of the most expensive low-voltage $315 \mathrm{~kW}$ converters have intentionally been chosen for the first and the second options, respectively, i.e., for the second option, the capital costs in practice may be even lower. Also, at a comparable economic effect of both options, implementing a low-voltage FC will pay off faster compared to a high-voltage one due to lower operating costs. To confirm this statement, the authors calculated and plotted payback (Figure 1) for two VFD implementing options. The Net Present Value (NPV) technique has been applied, which is well suited for the project analyzed, considering the inequality of effects (and costs) relating to different time instants $[26,27]$. NPV is the sum of the present values of the cash flows. The NPV indicator is the difference between the present values of all cash inflows and outflows (as of the investment project estimation moment). It shows the projected earnings an investor expects to receive from a project after the cash inflows have exceeded the initial investment costs and the recurrent cash outflows associated with implementing the project. When calculating NPV, 
an annual increase in the cost of electricity by $10 \%$ max. and a discount factor of 0.15 were considered. The estimated planning horizon was 7 years. For the $C F$ (Cash Flow), where $C F_{t}$ is the cash flow in t years $(t=1 \div N)$, and the $C I$ (Invested Capital) in the amount of $C I=-C F_{0}$, the Net Present Value is calculated by the formula:

$$
N P V=\sum_{t=0}^{N} \frac{C F_{t}}{(1+i)^{t}}=-C I+\sum_{t=1}^{N} \frac{C F_{t}}{(1+i)^{t}},
$$

where $i$ is the discount factor.

Figure 1 (a) shows that the low-voltage and high-voltage frequency converter options pay off in 5 and 6 years, respectively. Moreover, when building a curve approximation for these plots Figure 1 (b), it is seen that in another 5 years, the savings from implementing a low-voltage FC will exceed capital costs.
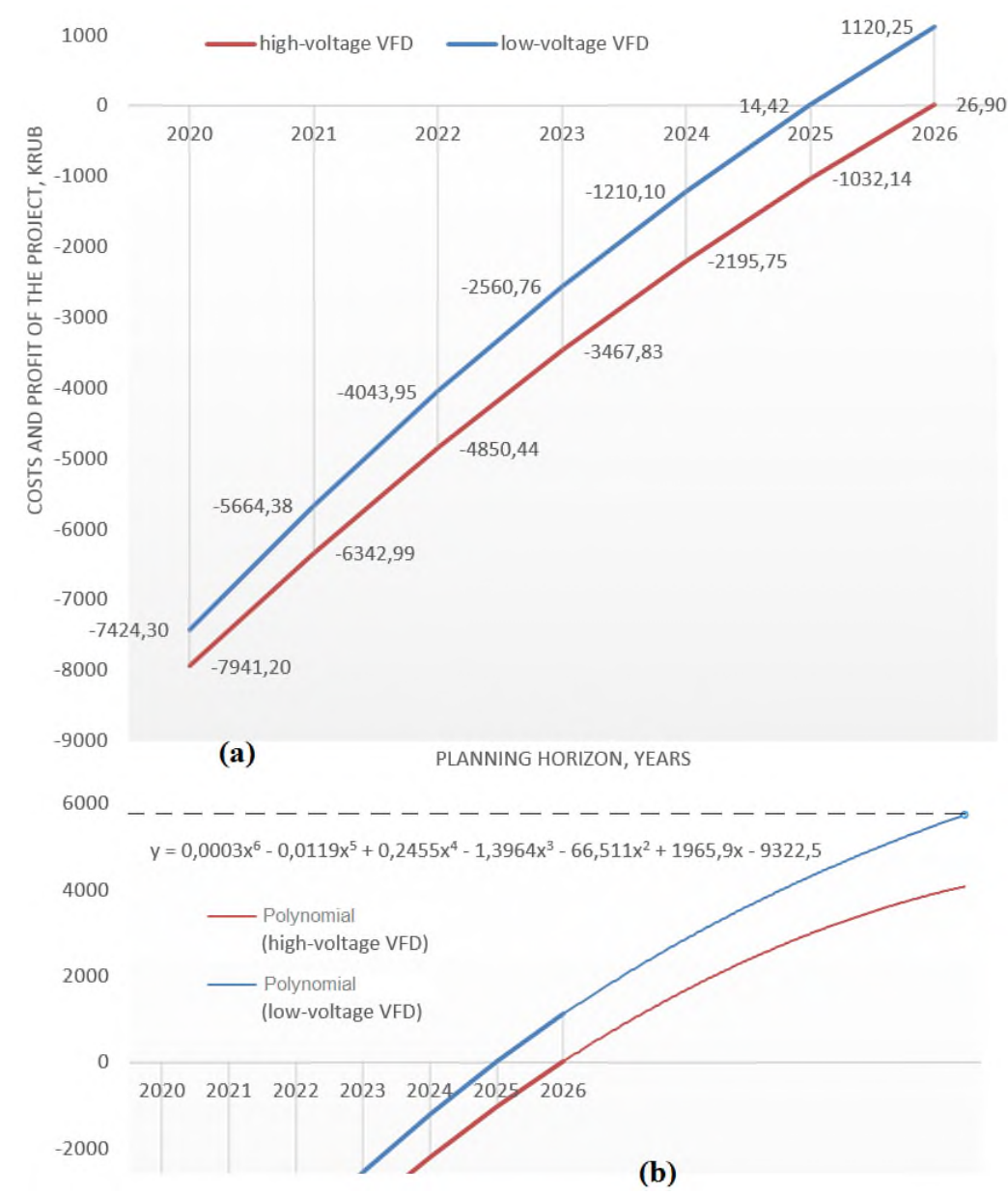

Fig. 1. Payback Plots for Two VFD Implementation Options: (a) payback period, (b) curve approximation.

The above examples confirm that when choosing an FC, many factors should be considered that will ensure its effective implementation and use at a particular process unit. First, the types, consequences, and criticality of equipment failures should be analyzed. This will allow ranking the diamond mining equipment by the criterion of the consequences 
and criticality of failures and reasonably implementing reliable expensive converters where their use is actually needed $[28,29]$.

Obviously, diamond mining equipment should be classified by the process requirements for the ED system, which will lead to a better formulation of technical specifications for the introduction of FCs. Also, based on the marketing research and the FC implementation and operation practice, the most common converter types should be ranked by the reliability and functionality criteria. The last example of implementing a high-voltage FC shows the feasibility of determining the electric drive power limit, at which low-voltage converters should be used [30].

\section{Conclusion}

The above approaches should form the basis of the guidelines for implementing the FCs in diamond mining. Such guidelines are intended to become a formalized knowledge base for the operator experts in the VFD application area.

It seems that large-scale and scrupulous research should develop in the below areas:

- process requirements for the diamond miner mechanisms;

- the FC operating specifics at these enterprises;

- the fundamental principles of building the FC power circuit;

- the fundamental VFD control principles;

- technical and economic marketing analysis for modern converters;

- research in the field of modern methods of gathering, processing, and analyzing data on the VFD system operation;

- semiconductor power converting equipment diagnostics techniques.

As a result of the work done, the practice of operating a variable-frequency drive at the diamond mining facilities and units has been analyzed. A technique is proposed to determine the feasible VFD system. As a result of the analysis, the problems of implementing and further improving the variable-frequency drive design have been formulated, the solution to which will improve the efficiency of using this drive type.

\section{References}

1. K. Fijorek, A. Jurkowska, I. Jonek-Kowalska, Resources Policy 70, 101965 (2021)

2. L. Filipishyna, N. Mihai, I. Tarasov, M. Andriienko, I.W.E. Arsawan, E3S Web of Conferences 201, 01015 (2020)

3. V.M. Zaernyuk, V.P. Leonova, E.N. Egorova, Lecture Notes in Networks and Systems 115, 580-588 (2020)

4. F. Villarreal-Guerrero, A. Pinedo-Alvarez, J. Flores-Velázquez, Computers and Electronics in Agriculture 174, 105515 (2020)

5. D. Brar, W.L. Kranz, T. Lo, S. Irmak, D.L. Martin, Transactions of the ASABE 62(5), 1395-1408 (2019)

6. R. Singh, H.K. Verma, Procedia Computer Science 125, 449-458 (2018)

7. E. Gultekin, C. Cinar, M. Okur, International Journal of Environmental Science and Technology 17(1), 455-462 (2020)

8. X. Chen, Z. Deng, S. Hu, J. Gao, X. Gao, Micromachines 11(1), 25 (2020)

9. T. Yamada, Y. Yang, P. Valnegri, I. Juric, A. Abnousi, K.H. Markwalter, A.N. Guthrie, A. Godec, A. Oldenborg, M. Hu, T.E. Holy, A. Bonni, Nature 569(7758), 708-713 (2019) 
10. O.A. Filina, A.N. Tsvetkov, P.P. Pavlov, D. Radu, V.M. Butakov, E3S Web of Conferences 124, 02002 (2019)

11. A.V. Dunaev, Mining Informational and Analytical Bulletin 2018(5), 144-150 (2018)

12. R. Liu, Y. He, Y. Zhao, X. Jiang, S. Ren, Automation in Construction 118, 103293 (2020)

13. N. Dutta, P. Kaliannan, U. Subramaniam, IOP Conference Series: Materials Science and Engineering 937(1), 012019 (2020)

14. W. Hassan, F. Mahmood, M. Akmal, M. Nasir, International Transactions on Electrical Energy Systems 30(9), e12481 (2020)

15. M. Thompson, M.F. Dahab, R.E. Williams, B. Dvorak, Journal of Environmental Engineering (United States) 146(7), 05020005 (2020)

16. U. Spangenberg, Vehicle System Dynamics 58(3), 404-424 (2020)

17. L. Latchoomun, C. Gokhool, R.T.F. Ah King, K. Busawon, J.P. Barbot, Lecture Notes in Electrical Engineering 561, 45-59 (2019)

18. A. Egorov, A. Semenov, Y. Bebikhov, A. Sigaenko, International Journal of Energy for a Clean Environment 20(2), 153-165 (2019)

19. A.S. Semenov, A.N. Egorov, V.M. Khubieva, 2019 International Conference on Industrial Engineering, Applications and Manufacturing (New York: Curran Associates, 8743025, 2019)

20. A.S. Semenov, A.N. Egorov, O.V. Fedorov, Proceedings - 2019 International Ural Conference on Electrical Power Engineering (New York: Curran Associates, 162-168, 8877664, 2019)

21. A. Dianov, A. Anuchin, International Journal of Power Electronics and Drive Systems 11(3), 1153-1164 (2020)

22. T. Jing, A. Radionov, A. Maklakov, V. Gasiyarov, Machines 8(3), 57 (2020)

23. B.I. Abramov, L.K. Datskovskii, I.K. Kuz'min, Y.V. Shevyrev, Russian Electrical Engineering 88(3), 159-165 (2017)

24. A.S. Semenov, A.N. Egorov, O.V. Fedorov, 2018 International Multi-Conference on Industrial Engineering and Modern Technologies (New York: Curran Associates, 8602676, 2018)

25. A.S. Semenov, A.N. Egorov, Y.S. Kharitonov, Y.V. Bebikhov, I.A. Yakushev, O.V. Fedorov, Proceedings - ICOECS 2019: 2019 International Conference on Electrotechnical Complexes and Systems (New York: Curran Associates, 8949997, 2019)

26. S. Abdelhady, Renewable Energy 168, 332-342 (2021)

27. A. Vrijdag, E.-J. Boonen, M. Lehne, Journal of Marine Engineering and Technology 18(3), 122-133 (2019)

28. A.N. Egorov, Y.S. Kharitonov, V.A. Shevchuk, A.S. Semenov, Bulletin of the Tomsk Polytechnic University, Geo Assets Engineering 331(6), 141-151 (2020)

29. G.I. Odnokopylov, V.A. Shevchuk, Y.N. Dementyev, Bulletin of the Tomsk Polytechnic University, Geo Assets Engineering 330(5), 131-140 (2019)

30. A. Semenov, I. Yakushev, Y. Kharitonov, V. Shevchuk, E. Gracheva, S. Ilyashenko, International Journal of Technology 11(8), 1537-1546 (2020) 